\title{
LOADS INTERACTION DOMAINS METHODOLOGY FOR THE DESIGN OF STEEL GREENHOUSE STRUCTURES
}

\author{
Sergio Castellano
}

\section{Introduction}

Greenhouse structures are a very competitive market, characterised by a high standardised production. In most common cases, manufacturers, in order to reduce production costs, assign a little number of different spans, usually $6.40 \mathrm{~m}, 9.60 \mathrm{~m}, 12.80 \mathrm{~m}$, and produce one greenhouse typology for each span. Design requirements are covered varying, with standardised length intervals, the height of columns (e.g. $h=3.0$ $3.5-4.0 \mathrm{~m})$ and the distance between frames (e.g. $\mathrm{i}=1.5-2 \cdot 0-2.5 \mathrm{~m})$. Also steel structural sections are standardised and only a little number of typologies are used, for instance circular or rectangular pipes, with a thickness of $1.5-3.0 \mathrm{~mm}$, are very common. It is strategic, for the manufacturers, to design and produce structures able to fulfil normative requirements and to optimize the ratio structural capacity/costs [2,7].

During 2001, the European Standard EN13031-1 "Greenhouse design and Construction Part I: Commercial production greenhouses" was approved by CEN/TC 284. The standard is based on relevant parts of structural Eurocodes, ENV1991-ENV1999 and complementary information is provided to account for the particular requirements, functions and forms of commercial production greenhouse that distinguish them from ordinary buildings. In Italy, it was approved by the National Standard Organization UNI in June 2002, whilst previous standards regarding design requirements of greenhouse structures, UNI 6781 and UNI 9936, were suppressed. The adoption of the standard reduced considerably the standardization uncertainty which characterised Italy with respect to other European Countries [1] and improved the competition of foreign manufacturer in our Country.

Aim of this research is to develop a design methodology which correlates the design parameters, whose production is characterised by high levels of

Paper received 06.04.2006; accepted 12.12.2006

Ing. SeRgio Castellano, ricercatore; Dip. PRIME, Università di Foggia <s.castellano@unifg.it>. standardization, such as the height of gutter or the distance between frames, with the actions on the greenhouse. The methodology, based on the use of charts and abacus, permits a clear and a direct interpretation of the structural response to design load combinations and allows the design of structural improvements aimed to the optimization of the ratio benefits (structural strength)/costs. The study of interaction structural domains requires high levels of engineering competences and appropriate calculation technology. The advantages of consequent design optimization consist in the reduction of costs, in terms of use of raw materials, of consumption of energy for the production and for the recycling at the dismissing of the greenhouse, of freight of structural elements and their installation, whose advantages are emphasised by the scale economy of the industrial production.

Charts and abacus, very friendly to use and to understand, are the output of the proposed methodology. They can be used also by non technicians in order to arrange a quick and reliable estimation of the costs of the structure. In any case, their use doesn't let off from the structural design which is necessary for each building but allow a high efficiency of the manufacturer in relations with customers.

The methodology will be developed basing on criteria assigned by EN13031-1 on two different kinds of greenhouse structures: an arched greenhouse with a film plastic covering and a duo pitched roof greenhouse covered with rigid plastic membranes.

\section{Definition of structural domains}

Main parameters involved in greenhouse structural design are: the covering materials, the geometrical and mechanical characteristics of the structure, the design loads, the minimum design working life period of the building, the location of the construction.

Depending on the design hypothesis about the mechanical behaviour of the structural material described by stress-strain curve and on the influence of displacements on the modelling of the frame, European structural standards provide different structural analy- 
sis: linear elastic, elastic with II order effects, elastoplastic, elasto-plastic with displacements effects. In any case it will be verified that a generic effect, $E_{d}$, such as stress, deformations, displacements, etc., induced on the structure by the design loads and depending on the analysed limit state, shall be less than corresponding design requirements, $\mathrm{R}_{\mathrm{d}}[8]$.

$$
\mathrm{E}_{\mathrm{d}} \leq \mathrm{R}_{\mathrm{d}}
$$

$E_{d}$ depends on a lot of parameters and can be expressed by (2).

$$
\mathrm{E}_{\mathrm{d}}=\mathrm{E}\left(\mathrm{S}_{\mathrm{d} 1}, \mathrm{~S}_{\mathrm{d} 2}, \ldots \mathrm{a}_{\mathrm{d} 1}, \mathrm{a}_{\mathrm{d} 2}, \ldots \mathrm{X}_{\mathrm{d} 1}, \mathrm{X}_{\mathrm{d} 2}, \ldots \gamma_{\mathrm{m}}, \gamma, \psi\right)
$$

where:

$\mathrm{S}_{\mathrm{di}}$ are the design loads (self weight, equipments, crops, snow actions, wind actions, etc.);

$\mathrm{a}_{\mathrm{di}}$ are the geometric parameters of the structure (height of the gutter and of the ridges, span, shape of the frame, section and thickness of structural elements, etc.);

$\mathrm{X}_{\mathrm{di}}$ are the design characteristics of structural material (Young modulus, ultimate and yield stress, etc.);

$\gamma_{m}$ is the safety coefficient of the structural material;

$\gamma \quad$ is the partial coefficient of actions [5];

$\psi \quad$ is the combination coefficient of actions [5];

With regard to Ultimate Limit State (ULS) analysis, performing linear elastic analysis, it shall be verified that in no structural sections the design stress exceeds the yield stress of the material reduced of its structural safety coefficient. In this case, applying equation (1), $\mathrm{E}_{\mathrm{d}}$ is the maximum stress, $\sigma_{\text {max }}$, calculated in the frame deriving from design structural analysis and $R_{d}$ is the design yield stress of the material, $\mathrm{f}_{\mathrm{yd}}$, obtained dividing the yield stress, $\mathrm{f}_{\mathrm{y}}$, for the safety coefficient of the structural material, $\gamma_{\mathrm{m}}$. The resistance criterion (1) is fulfilled if:

$$
\mathrm{E}_{\mathrm{d}}=\sigma_{\max } \leq \mathrm{R}_{e}=\mathrm{f}_{j,}=\frac{f_{r}}{\gamma_{w}}
$$

Elasto-plastic analysis provides an elasto-plastic behaviour of the structural material and analyse the collapse of the frame by means of plastic hinges or diffuse plasticity. The first method provides a linear increasing of loads and assign to the structural model an hinge in the section in which is reached the yield stress, the structure collapse for weakness due to the increasing of hinges. The diffuse plasticity method is adopted by FEM processors and it is assumed that the combination of design loads $\left(\mathrm{F}_{\mathrm{d}}\right)$ increases linearly. Consequently, also deformations increase, following the stress-strain curve assigned to the structural material, and it is assumed that the structure collapse if deformations induced by a load, F defined by (4), cause the loosing of convergence of the solution stiffness matrix.

$$
\mathrm{F}=\mathrm{k}_{\mathrm{l}} \mathrm{F}_{\mathrm{d}}
$$

It will be verified that the load multiplier, $\mathrm{k} 1$, is higher than 1.0 and the resistance criterion can be written as:

$$
\mathrm{E}_{\mathrm{d}}=\mathrm{F}_{\mathrm{d}} \leq \mathrm{R}_{\mathrm{d}}=\mathrm{k}_{\mathrm{l}} \mathrm{F}_{\mathrm{d}} \Rightarrow \mathrm{k}_{1} \geq 1.0
$$

Serviceability Limit State (SLS) analysis requires, in any case, a linear elastic behaviour of the structure, and it will be verified that displacements or deflections, $u$, of the structure, subject to design loads don't exceed corresponding standard requirements, $\mathrm{u}_{\mathrm{lim}},(6)$.

$$
\mathrm{E}_{\mathrm{d}}=\mathrm{u} \leq \mathrm{R}_{\mathrm{d}}=\mathrm{u}_{\text {lim }}
$$

If the geometric characteristics of the structure, the material and the loads acting on the structure are defined except for two, $S_{A}$ and $S_{B}, E_{d}$ depends only by $S_{A}$ and $S_{B}$ and the relation (2) can be written:

$$
\mathrm{E}_{\mathrm{d}}=\mathrm{E}\left(\Theta, \mathrm{S}_{\mathrm{A}}, \mathrm{S}_{\mathrm{B}}\right)=\mathrm{E}^{\prime}\left(\mathrm{S}_{\mathrm{A}}, \mathrm{S}_{\mathrm{B}}\right)
$$

where $\mathrm{Q}$ is a term taking into account all previously defined parameters.

Basing on these hypotheses, the global behaviour of a structure resisting to loads can be described in function of two generic actions $-\mathrm{S}_{\mathrm{A}}$ and $\mathrm{S}_{\mathrm{B}}-$ in the Cartesian plane by domains describing the mechanical behaviour of the structure in terms of stress levels or deformations.

The domain shape depends also on the kind of analysis performed (elastic, elasto-plastic, plastic of first or second order) and on the competent limit state. Domains are bounded by curves which will be defined Interaction Curves (IC). In ultimate limit states (ULS) analysis it is possible to define three different domains: the elastic; the elasto-plastic; the collapse. In serviceability limit states (SLS) only two domains will be defined: "serviceable" and "unserviceable".

\subsection{ULS structural domains}

Basing on previous hypothesis (3), if we define a Cartesian plane $\left(0, S_{A}, S_{B}\right)$ it is possible to describe the Elastic Domain which represents the locus of couples of actions $S_{A}$ and $S_{B}$ whose application on structure (4) involves that in no structural sections the yield stress is exceeded. In the same way it is possible to define the Elasto-Plastic Domain in which the combination of the couple of actions on the structure cause the plasticity of some section but not the collapse of the structure and the Collapse Domain to which belongs the couple of actions causing the collapse of the structure.

The curve which distinguishes the elastic from the elasto-plastic domain is defined as Elastic Interaction Curve (EIC), whilst it will be defined as Collapse Interaction Curve (CIC) the one which distinguishes the elasto-plastic from the collapse domain. The shape of structural domains will depend on the structural geometry, on the kind of loads applied, on the structural analysis performed and, more in general, on the structural standard adopted.

It is possible to draw interaction curves by interpolation assigning different values of the action $\mathrm{S}_{\mathrm{A}}\left(\mathrm{S}_{\mathrm{A} 1}\right.$, $\mathrm{S}_{\mathrm{A} 2}, \ldots \mathrm{S}_{\mathrm{An}}$ ) and calculating by means of the structural analysis the corresponding values of $\mathrm{S}_{\mathrm{B}}$ which cause 


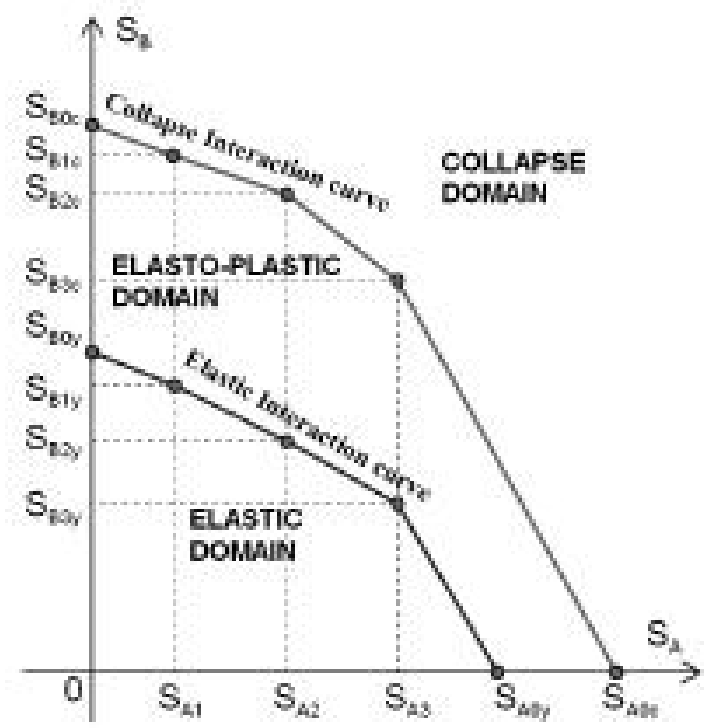

Fig. 1 - Example of the construction of interaction curves by means of interpolation of their points.

the exceeding of yield stress in one section $\left(\mathrm{S}_{\mathrm{B} 1 \mathrm{y}}\right.$, $\left.\mathrm{S}_{\mathrm{B} 2 \mathrm{y}}, \ldots, \mathrm{S}_{\mathrm{Bny}}\right)$ and the collapse of the structure $\left(\mathrm{S}_{\mathrm{B} 1 \mathrm{c}}\right.$ $\left.\mathrm{S}_{\mathrm{B} 2 \mathrm{c}}, \ldots, \mathrm{S}_{\mathrm{Bnc}}\right)$. The intersection with axes will be defined assigning $S_{A}=0$ or $S_{B}=0$ and calculating the corresponding values of $\mathrm{S}_{\mathrm{B}}\left(\mathrm{S}_{\mathrm{B} 0 \mathrm{y}}\right.$ and $\left.\mathrm{S}_{\mathrm{B} 0 \mathrm{c}}\right)$ and of $\mathrm{S}_{\mathrm{A}}$ $\left(\mathrm{S}_{\mathrm{A} 0 \mathrm{y}}\right.$ and $\left.\mathrm{S}_{\mathrm{A} 0 \mathrm{c}}\right)$.

On the same diagram, it is possible to represent a load sequence in the Cartesian plane by means of a directed polyline (load path). For each point of the plane, which represents a couple of loads acting on the structure, passes infinite load paths and it is possible to reach a load combination $\left(\mathrm{S}_{\mathrm{A} 0}, \mathrm{~S}_{\mathrm{B} 0}\right)$ by means of different "load history". In figure 2 are showed three different load paths, identified as 1,2 and 3 passing through $\mathrm{P}\left(\mathrm{S}_{\mathrm{AP}}, \mathrm{S}_{\mathrm{BP}}\right)$ where $\mathrm{S}_{\mathrm{AP}}$ and $\mathrm{S}_{\mathrm{BP}}$ represents the value of two different actions applied to the structure. Following load path " 1 " actions increase linearly from the origin to the point $\mathrm{P}$, the segment $\overline{O P}$ is included in the elastic domain and, consequently, in all the structural sections the stress value induced by the action of couple of actions belonging to the segment is lower than the yield one. It is possible to increase loads following load path " 1 " till the point "A", were the combination of actions cause the plasticization of the first structural section, and then until point $\mathrm{B}$ which represents the combination of actions which causes the structural collapse.

The load path " 2 " represents the case in which the

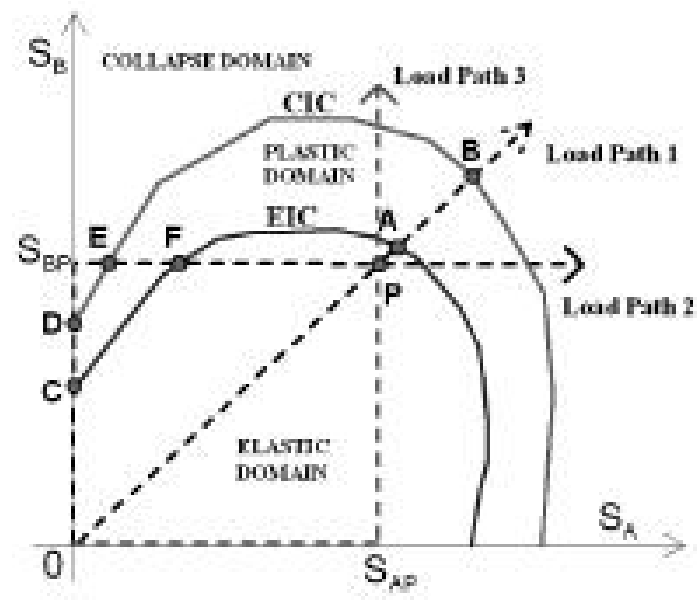

Fig. 2 - Three different load paths passing through $\mathrm{P}\left(\mathrm{S}_{\mathrm{AP}}, \mathrm{S}_{\mathrm{BP}}\right)$.

action $S_{B}$ increases its value from the origin to $S_{B P}$ and then, remaining $S_{B P}$ constant, only the action $S_{A}$ increases from zero to $\mathrm{S}_{\mathrm{AP}}$. During the first load step, $\overline{O S}_{B P}$, the first plastic hinges is formed in point " $C$ " whilst the structure collapse in " $\mathrm{D}$ ", meaning that, following the load path " 2 ", the structure is not able to reach the combination of action identified by point $P$. It is possible to reach the same load combination, identified by $\mathrm{P}$, by means of the load path 3 in which the action $S_{A}$ increases its value from the origin to $\mathrm{S}_{\mathrm{AP}}$ and then, remaining $\mathrm{S}_{\mathrm{AP}}$ constant, only the action $\mathrm{S}_{\mathrm{B}}$ increases from zero to $\mathrm{S}_{\mathrm{BP}}$, for the whole load path the structure is characterised by an elastic behaviour.

In real conditions, if we correlate wind loads to $\mathrm{S}_{\mathrm{A}}$ and snow load to $S_{B}$ and we associate the design combination of actions assigned by the standard to the point $\mathrm{P}$, the study of load paths provides very interesting information concerning the structural response to design loads. Load path 1 describes the case in which wind and snow actions increase linearly until the design values assigned by the standard, the structure is able to resist to this load increasing with an elastic behaviour. Load path " 2 " is equivalent to suppose that the snow falls without wind till the design value $S_{B P}$, afterwards the wind increases to reach the value $S_{A P}$, this sequence is not physically allowable because the structure collapse before to reach the snow design load. On the contrary it is possible to apply wind action first $\left(\mathrm{S}_{\mathrm{AP}}\right)$ and then snow load $\left(\mathrm{S}_{\mathrm{BP}}\right)$ remaining inside the elastic domain as described by load path 3 .

The load path analysis showed that the simultaneous increasing of wind and snow actions, load path

\begin{tabular}{|l|c|c|c|c|c|c|c|c|c|}
\hline & Permanent actions & \multicolumn{3}{c|}{$\begin{array}{c}\text { Permanently-present } \\
\text { installations }\end{array}$} & \multicolumn{3}{c|}{ Wind } & \multicolumn{3}{c|}{ Snow } & \multicolumn{2}{c|}{ Crop } \\
\hline a1) & $\gamma_{\mathrm{G} 1} G_{\mathrm{k} 1}$ & + & $\gamma_{\mathrm{G} 2} G_{\mathrm{k} 2}$ & + & $\gamma_{\mathrm{Q} 1} Q_{\mathrm{k} 1}$ & + & $\psi_{0 \mathrm{Q} 2} \gamma_{\mathrm{Q} 2} Q_{\mathrm{k} 2}$ & + & $\psi_{0 \mathrm{Q} 3} \gamma_{\mathrm{Q} 3} Q_{\mathrm{k} 3}$ \\
\hline $\mathrm{a} 2)$ & $\gamma_{\mathrm{G} 1} G_{\mathrm{k} 1}$ & + & $\gamma_{\mathrm{G} 2} G_{\mathrm{k} 2}$ & + & $\psi_{0 \mathrm{Q} 1} \gamma_{\mathrm{Q} 1} Q_{\mathrm{k} 1}$ & + & $\gamma_{\mathrm{Q} 2} Q_{\mathrm{k} 2}$ & + & $\psi_{0 \mathrm{Q} 3} \gamma_{\mathrm{Q} 3} Q_{\mathrm{k} 3}$ \\
\hline $\mathrm{b} 1)$ & $\gamma_{\mathrm{G} 1} G_{\mathrm{k} 1}$ & + & & + & $\gamma_{\mathrm{Q} 1} Q_{\mathrm{k} 1}$ & + & & + & \\
\hline
\end{tabular}

TABLE 1 - Combination of actions prescribed by EN13031. 


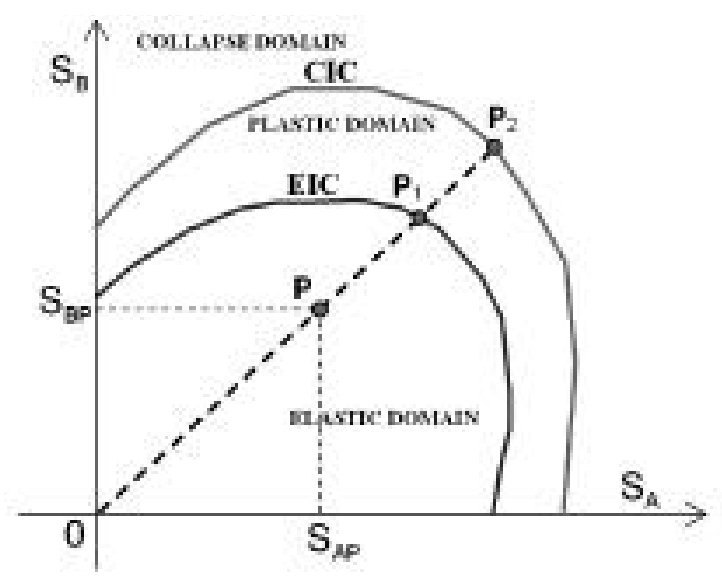

Fig. 3 - Definition of safety multiplier by means of structural domains.

" 1 ", could be less dangerous for the structure than the application of single actions such as described by load path " 2 ". It is very important during the design of the structure to analyse the whole load paths and not only the load combination assigned by the standards. In any case ENV1991-1 provides that design loads have to act linearly and simultaneously on the structure, therefore, in design situations only linear load path passing trough the origin of the axes will be allowable. Other load paths can be used for scientific purposes to better understand the structural behaviour of the frame or to calibrate structural standards.

Assigned a couple of loads, $\mathrm{S}_{\mathrm{AP}}$ and $\mathrm{S}_{\mathrm{BP}}$, acting on the structure identifying the point $\mathrm{P}\left(\mathrm{S}_{\mathrm{AP}}, \mathrm{S}_{\mathrm{BP}}\right)$ (Fig.3) inside the elastic domain, and named P1 and P2 the intersection of the prolongation of the segment $\overline{O P}$ with the Elastic Interaction Curve (EIC) and with the Collapse Interaction Curve (CIC), the ratio $\overline{O P}_{1} / \overline{O P}$ and $\overline{O P}_{2} / \overline{O P}$ represent, respectively, the safety multiplier for the elastic behaviour and for the collapse of the structure if the loads increase linearly. If the point " $P$ " corresponds to design loads, the segments $\overline{P P}_{1}$ and $\overline{P P}_{2}$ characterize the exceeding structural resources with respect to design conditions.

\subsection{SLS structural domains}

Greenhouses in which the cladding system is not tolerant to frame displacements, resulting from the design actions, are designated in EN13031-1 as Class A, and they require both ultimate and serviceability limit states design.

If the structure requires a Serviceability Limit States (SLS) analysis, in order to preserve the integrity of coverings and installations, the structural analysis will arrange that displacements and deflections are not exceeded under the design values of actions (6). The design combination for SLS describes serviceability conditions and is less burdensome than the ULS one. This variability is taken into account from the standard prescribing different values of partial and combination factors (Tabs. 1,2,3) for SLS and ULS. Displacements are defined as the change in the posi-

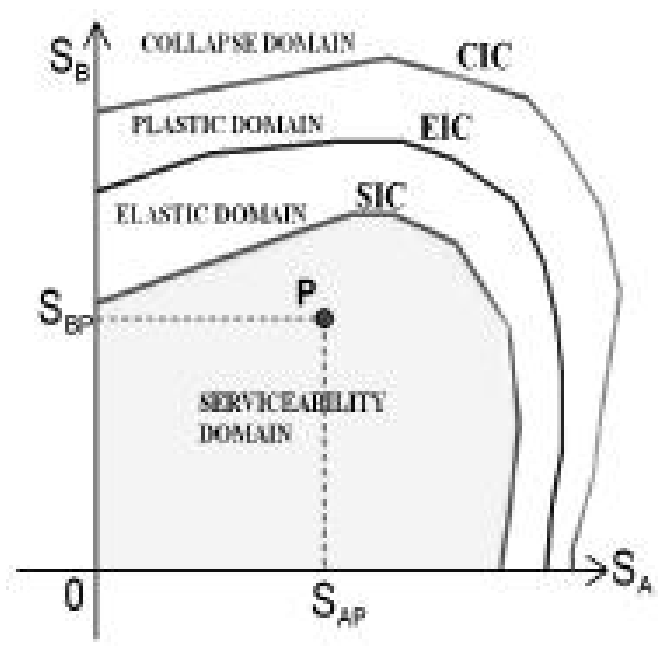

Fig. 4 - Definition of serviceability domain and of the Serviceability Interaction Curve (SIC).

tion of a point, whilst deflections can be defined as the deformation of a structural element perpendicular to the surface on which the action acts.

The structural standards provide specifications about limit values of displacements and deformations of: connecting points of columns with foundations; elements at gutter level and on the roof. In those cases it is possible to define a "serviceability" and a "unserviceable" domain. At the "serviceability" domain belongs all those load combinations, identified by points, for which are not exceeded the limit deformations or displacements prescribed by the standard (Fig. 4). The shape of serviceability domain will depend on the structural shape, on the kind of loads applied, on the structural analysis performed and, more in general, on the structural standard adopted. The curve which distinguishes the "serviceability" from the "break" domain is defined Serviceability Interaction Curve (SIC). Usually the Elastic Domain includes the Serviceability Domain. Also in this case it is possible analyse the structural behaviour by means of load paths and to identify safety multiplier with respect to serviceability limit states.

\section{Materials and methods}

\subsection{Greenhouses structural domains}

Basing on previous considerations, it is possible to define the interaction domains for greenhouses structures. The design will be based on the European Standard EN13031-1 "Greenhouse design and Construction Part 1 : Commercial production greenhouses". Two typologies of mono-span greenhouses will be analysed: a Class B arched frame usually covered by plastic film and a Class A duo-pitched roof greenhouse covered by rigid cladding panels. It will be assumed for both structures a minimum reference period of actions of 15 years.

The dimensions of the steel arch were: $\mathrm{h}=255 \mathrm{~cm}$; 


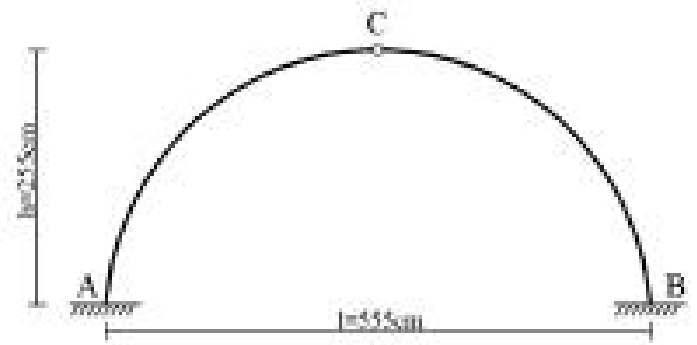

Fig. 5 - Structural model of the arched greenhouse. A and B are fixed whilst $\mathrm{C}$ is a ridge pin joint.

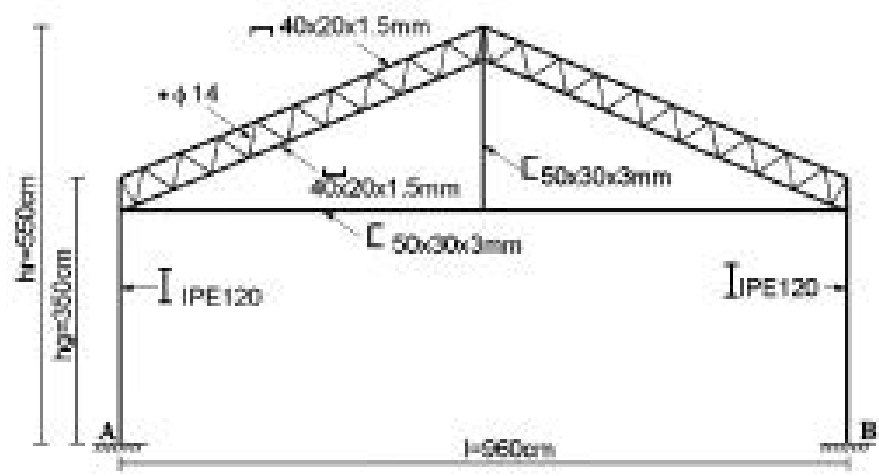

Fig. 6 - Structural model and sections of the duo-pitched roof greenhouse. A and B are fixed joint.

$\mathrm{l}=555 \mathrm{~cm}$ (Fig. 5 ); pipe section of diameter $\mathrm{f}=40 \mathrm{~mm}$ and thickness $\mathrm{s}=1.8 \mathrm{~mm}$; distance from frames, $\mathrm{i}=1.50 \mathrm{~m}$. Dimensions of duo-pitched roof greenhouse were: height of the gutter $h g=350 \mathrm{~cm}$, height of the ridge $\mathrm{hr}=550 \mathrm{~cm}$, span $\mathrm{l}=960 \mathrm{~cm}$ (Fig. 6), in calculations it was assumed a distance of frames $\mathrm{i}=3.65 \mathrm{~m}$.

All design values of actions that may occur simultaneously shall be considered in combination.

$$
\mathrm{F}_{\mathrm{d}}-\sum_{j=1} \gamma_{\mathrm{C}_{\mathrm{j}}} \mathrm{G}_{\mathrm{kj}}+\sum_{i=1} \gamma_{Q_{i}} \psi_{\mathrm{ai}} \mathrm{Q}_{\mathrm{ki}}
$$

where:

$\mathrm{F}_{\mathrm{d}} \quad$ is the design load acting on the structure;

$\mathrm{G}_{\mathrm{kj}}$ is the characteristic value of permanent and permanently present actions;

$\mathrm{Q}_{\mathrm{ki}}$ is the characteristic value of live actions (wind, snow, crops, concentrated vertical loads, incidentally present installation, thermal actions, etc.);

$\gamma_{\mathrm{Gj}}$ is the partial factor depending on the safety coefficient, on the limit state studied and on the kind of use of the structure;

$\psi_{0 \mathrm{i}}$ is the combination coefficient depending on the occurrence that more actions act simultaneously.

The standard assigns different combination of actions, and in this research it will be considered only "a1", "a2", and "b1" in which are considered the combination of climatic and crop loads (Tab. 1).

Partial and combination coefficients are assigned by each Country in EN13031-1 having into account

\begin{tabular}{|l|c|c|c|}
\hline \multicolumn{2}{|l|}{ Limit state classification } & \multirow{2}{*}{ SLS } & \multirow{2}{*}{ ULS } \\
\cline { 1 - 2 } Name & Symbol & & \\
\hline Permanent actions & $\gamma_{\mathrm{G} 1}$ & 1,0 & 1,2 \\
\hline $\begin{array}{l}\text { Permanently- } \\
\text { present } \\
\text { installation } \\
\text { actions }\end{array}$ & $\gamma_{\mathrm{G} 2}$ & 1,0 & 1,2 \\
\hline Wind actions & $\gamma_{\mathrm{Q} 1}$ & 1,0 & 1,2 \\
\hline Snow actions & $\gamma_{\mathrm{Q} 2}$ & 1,0 & 1,2 \\
\hline Crop actions & $\gamma_{\mathrm{Q} 3}$ & 1,0 & 1,2 \\
\hline
\end{tabular}

TABLE 2 - Partial coefficients $\gamma$ for Italy prescribed by EN13031.

\begin{tabular}{|c|c|c|c|}
\hline & \multicolumn{3}{|c|}{ Combination coefficients $\psi$} \\
\hline $\begin{array}{c}\text { Combination of } \\
\text { actions }\end{array}$ & wind & snow & crop \\
$\psi_{0 \mathrm{Q} 1}$ & $\psi_{0 \mathrm{Q} 2}$ & $\psi_{0 \mathrm{Q} 3}$ or $\psi_{2 \mathrm{Q} 3}$ \\
\hline $\mathrm{a} 1$ & - & 0,6 & 1,0 \\
\hline $\mathrm{a} 2$ & 0,6 & - & 1,0 \\
\hline
\end{tabular}

TABLE 3 - Combination coefficients $\psi$ for Italy prescribed by EN13031.

the parameters which affect safety levels of commercial production greenhouses: human occupancy restricted to low levels of authorised personnel; minimum design working life less than ordinary buildings.

Taking into account coefficients prescribed by the standard (Tabs. 2, 3) load combination can be written as:

a1) $1.2 \mathrm{G}_{\mathrm{k} 1}+1.2 \mathrm{G}_{\mathrm{k} 2}+1.2 \mathrm{Q}_{\mathrm{k} 1}+0.72 \mathrm{Q}_{\mathrm{k} 2}+1.2 \mathrm{Q}_{\mathrm{k} 3}$

a) $1.2 \mathrm{G}_{\mathrm{k} 1}+1.2 \mathrm{G}_{\mathrm{k} 2}+0.72 \mathrm{Q}_{\mathrm{k} 1}+1.2 \mathrm{Q}_{\mathrm{k} 2}+1.2 \mathrm{Q}_{\mathrm{k} 3}$

b1) $1.2 \mathrm{G}_{\mathrm{k} 1}+1.2 \mathrm{G}_{\mathrm{k} 2}+1.2 \mathrm{Q}_{\mathrm{k} 1}$

for ULS analysis and:

a1) $1.0 \mathrm{G}_{\mathrm{k} 1}+1.0 \mathrm{G}_{\mathrm{k} 2}+1.0 \mathrm{Q}_{\mathrm{k} 1}+0.6 \mathrm{Q}_{\mathrm{k} 2}+1.0 \mathrm{Q}_{\mathrm{k} 3}$

a2) $1.0 \mathrm{G}_{\mathrm{k} 1}+1.0 \mathrm{G}_{\mathrm{k} 2}+0.6 \mathrm{Q}_{\mathrm{k} 1}+1.2 \mathrm{Q}_{\mathrm{k} 2}+1.0 \mathrm{Q}_{\mathrm{k} 3}$

b1) $1.0 \mathrm{G}_{\mathrm{k} 1}+1.0 \mathrm{G}_{\mathrm{k} 2}+1.0 \mathrm{Q}_{\mathrm{k} 1}$

for the SLS analysis.

The structural material was, in both cases, cold formed steel of Fe360 class characterised by: Young Modulus $E=205000 \mathrm{MPa}$, yield stress $\mathrm{f}_{\mathrm{y}}=235 \mathrm{~N} / \mathrm{mm}^{2}$, ultimate stress $f_{u}=360 \mathrm{~N} / \mathrm{mm}^{2}[5]$.

Structural analysis was performed by means of a FEM software (ANSYS) and a linear elastic analysis and a plastic analysis was carried out to evaluate the collapse of the structure. The safety coefficient of the material depends on the analysis performed, basing on provisions of ENV1991-1, it is assumed $\mathrm{g}_{\mathrm{m}}=1.0$ for linear elastic analysis and $\mathrm{g}_{\mathrm{m}}=1.1$ for plastic analysis: the design value of the yield stress of the steel is given by (15).

$$
\mathrm{f}_{\mathrm{dy}}=\mathrm{f}_{\mathrm{y}} / \gamma_{\mathrm{m}}
$$

Greenhouses are characterised by a high ratio between live and permanent actions and in most common cases climatic loads, such as wind and snow, are critical for greenhouse design [9, 10], while crop loads have a short variability in the time. For this reason structural domains (Fig. 4) will be evaluated con- 


\begin{tabular}{|l|c|l|l|}
\hline $\begin{array}{l}\text { Greenhouse } \\
\text { typology }\end{array}$ & Permanent & $\begin{array}{l}\text { Perm. } \\
\text { present } \\
\text { inst. }\end{array}$ & Crop \\
\hline Arched & 20 & 50 & 150 \\
\hline Duo-pitched & 70 & 150 & 150 \\
\hline
\end{tabular}

TABLE 4 - Values of constant uniform loads $\left(\mathrm{N} / \mathrm{m}^{2}\right)$ applied on the investigated structures.

sidering as constant actions the permanent, the permanently present installations and the crop loads, whilst the characteristics values of wind $\left(\mathrm{Q}_{\mathrm{k} 1}\right)$ and snow $\left(\mathrm{Q}_{\mathrm{k} 2}\right)$ actions will be considered as variable. Climatic loads depend on the geometry of the structure and on the region in which will be built the greenhouse. In this calculation it was supposed that the greenhouse will be located in southern Italy, in Puglia, in open flat countryside, on the see level corresponding to the area III for the snow load and to the area 3 for the wind action [5].

\section{Results and discussions}

\subsection{Arched steel greenhouse}

The definition of structural domains of arched frame highlights that the combination of climatic actions "a1" - wind dominant and snow- and "a2" snow dominant and wind- assigned by EN13031-1 belong to the elastic domain whilst "b1" - wind dominant- combination showed the collapse of the structure meaning that the structure doesn't fulfil the standard requirements (Fig. 7).

The values of safety factors (Tab. 5) and the shape of structural domains show a better capability of the structure to resist to vertical loads, such as snow loads, then to horizontal one, such as wind actions.

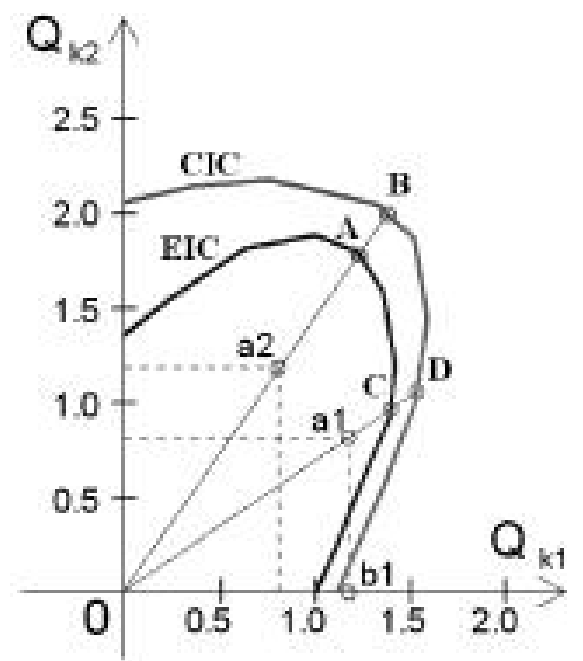

Fig. 7 - Structural domains of arched structure with a distance of frames, $\mathrm{i}=1.50 \mathrm{~m}$, in function of characteristics values of wind $\left(\mathrm{Q}_{\mathrm{k} 1}\right)$ and snow $\left(\mathrm{Q}_{\mathrm{k} 2}\right)$ actions. Points a1 $(1,2 ; 0,72)$, a2 $(0,72 ; 1,2)$ and b1 $(1,2$; $0)$ correspond to load combinations prescribed by EN13031-1.

\begin{tabular}{|c|c|c|}
\hline \multirow[b]{2}{*}{$\begin{array}{l}\text { Load } \\
\text { combinations }\end{array}$} & \multicolumn{2}{|c|}{ Safety Factors } \\
\hline & Elastic analysis & $\begin{array}{l}\text { Elasto-plastic } \\
\text { analysis }\end{array}$ \\
\hline a1 & $\frac{0 C}{\overline{0 a 1}}=1.50$ & $\overline{\overline{0 D}}=1.67$ \\
\hline a2 & $\frac{\overline{0 A}}{\overline{0 a 2}}=1.16$ & $\frac{\overline{0 B}}{\overline{0 a 2}}=1.30$ \\
\hline b1 & $<1.0$ & $<1.0$ \\
\hline
\end{tabular}

TABLE 5 - Safety factors of arched structure for "a1", "a2" and "b1" load combinations.

Moreover, the climatic load distribution on the structure prescribed by EN13031-1 is such that the combination of climatic actions is less dangerous for the structure than their individual application.

Structural domains analysis allows also to evaluate very easily how the designer can modify the structure in order to resist to load combination prescribed by the norm and in which climatic region the structure will be located.

In the first case it is possible to analyse the modifications of structural domains changing, for instance, the distance of frames - in our example it was assumed $\mathrm{i}=1.50 \mathrm{~m}$. If we limit the analysis to elastic domains, the variation of the distance between frames, without any changing of structural frames, is proportional to the variation of the climatic loads acting on the structure. Loads and stress vary linearly in the elastic analysis therefore the elastic interaction curves, corresponding to different values of the distance between frames, are homothetic with respect to the origin of axes (Fig. 8). The analysis highlights that this kind of greenhouse typology is able to resist to design loads assigned by EN13031-1 in this specific climatic region only with a distance of frames of $1.0 \mathrm{~m}$.

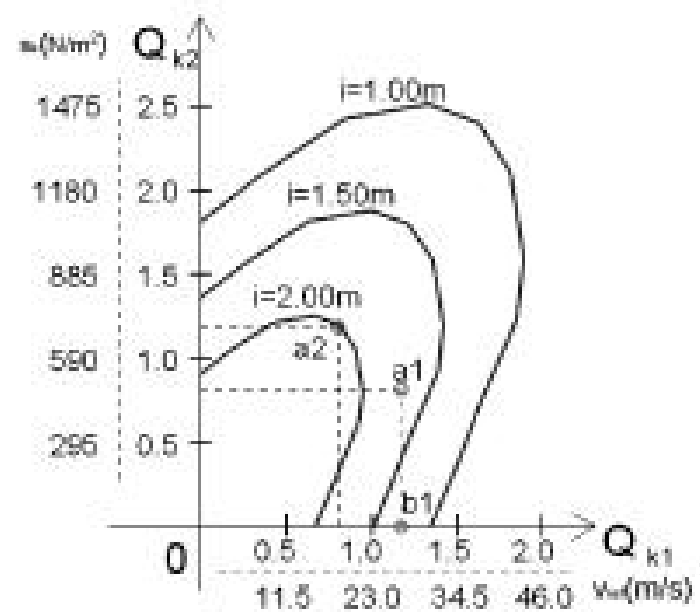

Fig. 8 - Elastic Interaction Curves of arched structure relating to a distance of frames, $\mathrm{i}=1.0 \mathrm{~m}, \mathrm{i}=1.50 \mathrm{~m}, 2.0 \mathrm{~m}$. Points a1 $(1,2 ; 0,72)$, $\mathrm{a} 2(0,72 ; 1,2)$ and b1 $(1,2 ; 0)$ correspond to load combinations prescribed by EN13031-1. 


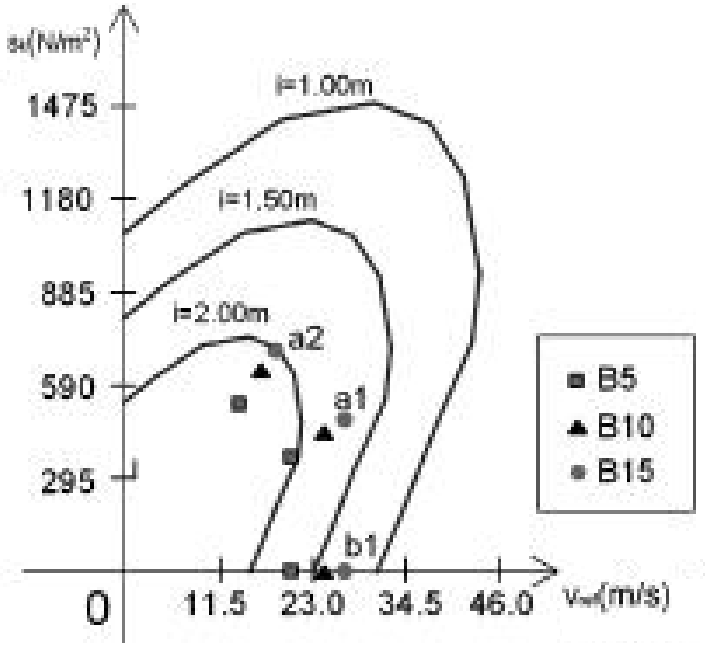

Fig. 9 - Elastic Interaction Curves of arched structure relating to a distance of frames, $\mathrm{i}=1.0 \mathrm{~m}, \mathrm{i}=1.50 \mathrm{~m}, 2.0 \mathrm{~m}$. Points a1 $(1,2 ; 0,72)$, $\mathrm{a} 2(0,72 ; 1,2)$ and $\mathrm{b} 1(1,2 ; 0)$ correspond to load combinations prescribed by EN13031-1for classes B5, B10 and B15.

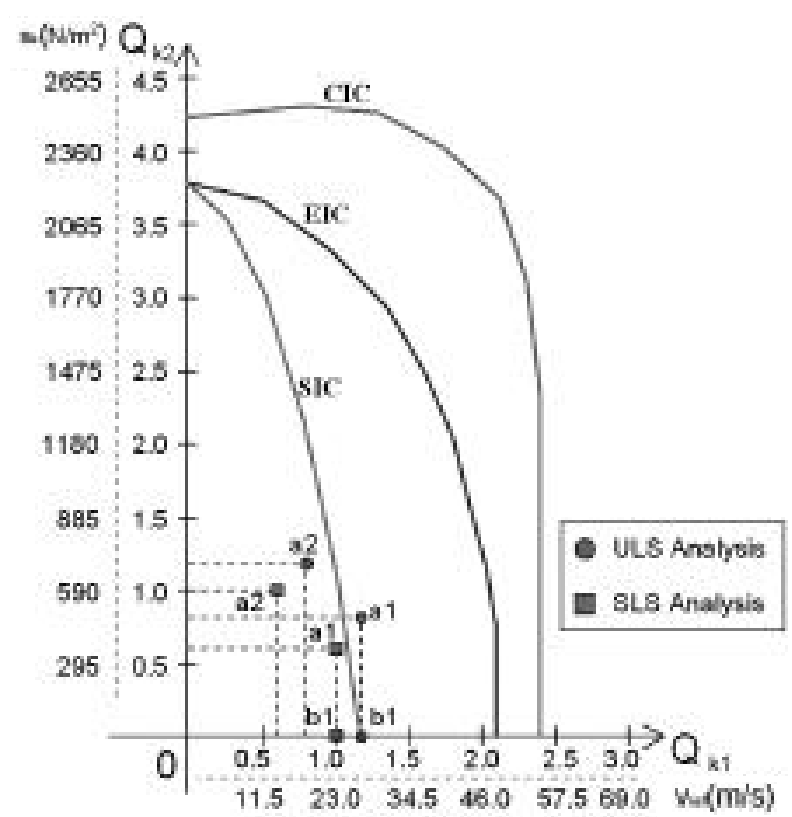

Fig. 10 - Structural domains of a duo-pitched roof greenhouse and serviceability (SIC), elastic (EIC) and collapse (CIC) interaction curves. In the diagram, points corresponding to EN13031 design requirements for ULS and SLS analysis are shown.

With the same methodology it is possible to evaluate in which climatic region the structural typology fulfils the requirements of EN13031-1. It is sufficient to indicate on the axes the value of actions and not their ratio with respect to the characteristic values of climatic actions (Figs. 8, 9). In our calculations it was assumed that the structure had to be designed in southern Italy, on sea level, in area III for the snow and 3 for the wind. This corresponds, with a minimum return period of climatic actions of 15 years, with a characteristic value of snow action on the soil of $s_{k}=590 \mathrm{~N} / \mathrm{m}^{2}$, corresponding in our calculations with $\mathrm{Q}_{\mathrm{k} 2}=1.0$, and to a characteristic value of wind speed of $\mathrm{v}=23 \mathrm{~m} / \mathrm{s}$, corresponding in our calculations with $\mathrm{Q}_{\mathrm{k} 1}=1.0$ (Figs. 8 and 9).

Consequently, for the designer it will be possible to evaluate $\mathrm{Q}_{\mathrm{k} 1}$ and $\mathrm{Q}_{\mathrm{k} 2}$ corresponding to different climatic regions, to draw in the chart the corresponding combination of actions and, finally, to verify if points belongs to the elastic domain of a specific typology. For instance the analysed arched greenhouse could be used in a region characterised by low values of reference wind speed.

It is possible to use the same chart (Fig.9) to evaluate characteristic values of wind and snow loads in function of minimum reference return period of actions. Basing on formulas assigned by ENV1991-1, it is possible to evaluate the points "a1", "a2" and "b1" corresponding to the couple of design actions with a return periods of 10 and 5 years (Fig. 9). The same diagram shows that the typology with $\mathrm{i}=1.50 \mathrm{~m}$ fulfils standard requirements for B5 class structure (Fig. 9). Moreover, the shape of structural domains suggests to the designer that with local improvement of the structure the same typology could be classed as B10 because load combination "b1" for a return period of 10 years is very close to the elastic interaction curve of $\mathrm{i}=1.50 \mathrm{~m}$ typology.

\subsection{Duo-pitched roof steel greenhouse}

By means of structural design were defined the Collapse Interaction Curve (CIC), the Elastic Interaction Curve and of the Serviceability Interaction Curve (SIC). The curves were drawn in a Cartesian reference frame having on " $x$ " axis the characteristic load $\mathrm{Q}_{\mathrm{k} 1}$, or the corresponding reference wind speed whilst on " $y$ " axis were indicated the characteristic load $Q_{k 2}$, or the corresponding snow load on the soil. Moreover, were shown the points corresponding to design combinations, "a1", "a2" and "b1" assigned by EN13031 with regard to ULS and SLS (Fig.10) different values are due to the combination factors of action prescribed by the standard for the ULS $(\gamma=1.2)$ and for SLS $(\gamma=1.0)$.

The standard provides specifications about limit values of displacements of: connecting points of columns with foundations; elements at gutter level and on the roof. Displacements of the roof and at gutter level depend on the clearances of the cladding panels in the side wall and in the gable wall. The limiting values shall be determined from the tolerance to movements of the cladding panel within its cladding bars and shall be calculated taking account of the nominal dimensions for length and width of the cladding panel and the clearances. Generally displacements of a greenhouse might also be limited by the use of the equipments moving through the greenhouse. Limiting values of deflections of gutters, girders and ridges; rafters and trellis girders; structural components directly supporting cladding panels of gable walls and side walls cladding (glazing) bars are provided by the EN13031-1. Maximum value of deflections depends on the length of the element. 


\begin{tabular}{|c|c|c|c|}
\hline \multirow{2}{*}{$\begin{array}{l}\text { Load } \\
\text { combination }\end{array}$} & \multicolumn{3}{|c|}{ Safety Factors } \\
\cline { 2 - 4 } & $\begin{array}{c}\text { SLS } \\
\text { Elastic } \\
\text { analysis }\end{array}$ & $\begin{array}{l}\text { Elastic } \\
\text { analysis }\end{array}$ & Elasto-plastic \\
\hline a1 & 1.07 & 1.65 & 2.01 \\
\hline a2 & 1.50 & 2.04 & 2.77 \\
\hline b1 & 1.16 & 1.78 & 2.04 \\
\hline
\end{tabular}

TABLE 6 - Safety factors of duo-pitched roof structure for "a1", "a2" and "b1" load combinations with regard to serviceability limit state (SLS) and ultimate limit state (ULS) analysis.

The points corresponding to ULS analysis design combinations are inside the elastic domain, also load combinations corresponding to the SLS analysis are included inside the seviceability domain meaning that the analysed structural typology fulfils requirements of EN13031 concerning both SLS and ULS analysis (Fig. 10).

In all cases the shape of structural domains is lengthened to the " $y$ " axe highlighting a better capability of the structure to resist to vertical loads then to horizontal one especially with regard to the serviceability limit state analysis as described from the comparison of the ratio of the intersection with axes of the interaction curves: $\mathrm{Q}_{\mathrm{k} 2} / \mathrm{Q}_{\mathrm{k} 1}=1.7$ for CIC; $\mathrm{Q}_{\mathrm{k} 2} / \mathrm{Q}_{\mathrm{k} 1}=1.8$ for EIC; $\mathrm{Q}_{\mathrm{k} 2} / \mathrm{Q}_{\mathrm{k} 1}=3.1$ for SIC (Fig. 10).

With regard to ULS, the CIC and the EIC behaviour shows that the structural characteristics of the steel frame provides very high safety levels with regard to load combinations "a1", "a2" and "b1" prescribed by EN13031 (Tab.6). The SIC highlights that the safety levels are very high also for serviceability analysis with regard to vertical loads, whilst the curve is very close to the load combination "a1" of "SLS". The shape of domains highlights that, with respect to design loads, the structural resources are higher for vertical loads than horizontal ones, moreover the safety level with regard to SLS analysis is lower then the ULS one. This result confirms that in the design of greenhouses in which the cladding system is not tolerant to frame displacements, resulting from the design actions, the serviceability limit state analysis is usually more restrictive than the ultimate limit state [3].

Concerning serviceability analysis it is interesting to highlight that for vertical actions the deformations exceed standard requirements when the first plastic hinge is formed due to the application of vertical loads (Fig. 10) and that the serviceability domain is completely included inside the elastic one.

The shape of structural domains highlight that structural sources are not sufficiently exploited due to the safety factors of ULS are almost the 70\% higher then the SLS one (Tab. 6). It will be possible to optimise the design of the structure increasing its stiffness and conforming together ULS and SLS safety factors with a consequent reduction of its cost.

\section{Conclusions and perspectives}

The study of structural interaction domains allowed a clear and a direct interpretation of the structural response to design load combinations. The diagrams highlight not only if the structure fulfils the standard requirements but also the safety levels with respect to design load combinations and allow the structural designer how to operate in order to optimize the structural response with standard requirements achieving the best ratio benefits (structural safety)/ costs. Moreover, the shape of structural domains provides information concerning the exploitation of structural resources and, consequently, how to operate to optimize the structural design.

Structural interaction domains for arched greenhouse showed a better capability of the structure to resist to vertical loads then to horizontal one. Moreover, the climatic load distribution on the structure assigned by EN13031 is such that the combination of climatic actions is less dangerous for the structure then their individual application. Duo pitched roof steel greenhouse interaction domains, showed a better capability of the structure to resist to vertical loads then to horizontal one and that, in any case, the serviceability limit states analysis is more strict then the ULS one. The shape of structural domains highlighted that the combination of actions is more dangerous for the structure then the application of single loads and that structural sources are not sufficiently exploited. Abacus showed that the safety factors of ULS are almost the $70 \%$ higher then the SLS one: it will be possible to optimise the design of the structure increasing its stiffness and conforming ULS and SLS safety factors with a consequent reduction of its cost.

Charts and abacus very easy to interpret and can be used also by non technicians in order to arrange a quick and reliable estimate of the costs of the structure. For instance, it is sufficient to know characteristic values of snow loads and wind speed to evaluate what is the distance of frame of the arched greenhouse to fulfil EN13031 requirements.

The structural domain methodology represents an effective tool for the designer to improve and optimize the structural typology, in any case it cannot to replace the structural design which is necessary for each building and depends on specific parameters such as the interaction of foundations with the structure, specific loads applied on the structure, conformation of the land to evaluate in any different case.

\section{References}

[1] Castellano S., Scarascia Mugnozza G., Analisi e progetto agli stati limite delle strutture portanti per serre alla luce dei nuovi standard europei, Atti del seminario AIIA "Le colture protette: aspetti agronomici, territoriali e tecnico-costruttivi" (1999), Ragusa, Italy, 24-26 giugno, 121-135. 
[2] Castellano S., Scarascia Mugnozza G., The influence of the structural design in the greenhouse quality management, Proceedings of the International workshop "XXX Congress Ciosta-Cigr V" (2003), Torino, Italy, 22-24 Settembre, 832-839;

[3] Castellano S., A. Candura, Scarascia Mugnozza G., Greenhouse structures SLS analysis: experimental results and normative aspects, Acta Horticulturae (2005) 691, 701-708, ISSN 0567-7572, ISBN 906605-6306

[4] EN 13031-1 Greenhouse design and Construction Part 1: Commercial production greenhouses, CEN European Committee for Standardization (2001), Bruxelles.

[5] ENV 1991 Eurocode 1 Basis of design and actions on structures. CEN - European Committee for Standardization (1991), Bruxelles.

[6] ENV 1993 Eurocode 3 Design of steel structures. CEN - European Committee for Standardization (1993), Bruxelles.

[7] Gusman A., Marucci A, Lagrimino M., Analisi strutturale dei tunnel coperti con film plastico, Rivista di Ingegneria Agraria (2005) 36 (4), 87-96.

[8] Pozzati P., Teoria e Tecnica delle Strutture, (1995) Vol.1, UTET, Torino.

[9] Robertson, A.P., HoXey, R.P.. Structural design of greenhouses with an emphasis on wind loading, $\mathrm{Pa}-$ per workshop on European greenhouse standards (1992), Barcelona, Spain, 49-57.

[10] Scarascia Mugnozza G. Castellano S., RobertSon A.P., Roux P., Gratraud J., Dufresne de Virel M., PALIER, P., Snow shape coefficients for greenhouse structures, Rivista di Ingegneria Agraria (2003) 34 (2), 3-12.

\section{SUMMARY}

Aim of this research is to develop a design methodology which correlates main structural design parameters, whose production is characterised by high levels of standardization, such as the height of gutter or the distance between frames, with actions on the greenhouse. The methodology, based on the use of charts and abacus, permits a clear and a direct inter- pretation of the structural response to design load combinations and allows the design of structural improvements with the aim of the optimization of the ratio benefits (structural strength)/costs.

The study of structural interaction domains allowed a clear and a direct interpretation of the structural response to design load combinations. The diagrams highlight not only if the structure fulfils the standard requirements but also the safety levels with respect to design load combinations and allow the structural designer how to operate in order to optimize the structural response with standard requirements achieving the best ratio benefits (structural safety)/ costs. The methodology was developed basing on criteria assigned by EN13031 on two different kinds of greenhouse structures: an arched greenhouse with a film plastic covering and a duo pitched roof greenhouse cover with rigid plastic membranes.

Structural interaction domains for arched greenhouse showed a better capability of the structure to resist to vertical loads then to horizontal one. Moreover, the climatic load distribution on the structure assigned by EN13031 is such that the combination of climatic actions is less dangerous for the structure then their individual application. Whilst, duo pitched roof steel greenhouse interaction domains, showed a better capability of the structure to resist to vertical loads then to horizontal one and that, in any case, the serviceability limit states analysis is more strict then the ULS one. The shape of structural domains highlighted that the combination of actions is more dangerous for the structure then the application of single loads.

Charts and abacus very easy to interpret and can be used also by non technicians in order to arrange a quick and reliable estimate of the costs of the structure. For instance, it is sufficient to know characteristic values of snow loads and wind speed to evaluate what is the distance of frame of the arched greenhouse to fulfil EN13031 requirements.

\section{Key words:}

Greenhouse, structure, design, interaction curves. 
